\title{
Classical dialogs in CSCL
}

\author{
Gerry Stahl • Friedrich Hesse
}

Published online: 3 July 2009

(C) International Society of the Learning Sciences, Inc.; Springer Science + Business Media, LLC 2009

\section{Ode on a Grecian conference}

Upon the shore of the Aegean Sea, amidst the splendor of ancient Rhodes, the CSCL community convened in June to mix futuristic stabs at truth with classic vistas of natural beauty. Preceded by the first daylong retreat of ISLS, two-and-a-half days of pre-conference events brought together groups of researchers in 16 workshops, tutorials, and seminars, including a doctoral consortium and an early-career workshop. The "Intro to CSCL" tutorial engaged over 30 newcomers to CSCL in a collaborative learning dialog with 18 members of the ijCSCL Editorial Board.

The three full days of the main conference included the whole variety of events typical of CSCL conferences: long and short papers, demos, interactive posters, panels, symposia, and invited keynote talks. The conference concluded with a panel on the beginnings of CSCL 20 years ago in nearby Italy - highlighting both the growth of the field and the continuity of concerns. With perfect weather, an ocean beach, swimming pools, and an open bar, the conference was pervaded by a particularly friendly and informal atmosphere. Scaffolded by good Greek food and drink, meals were always stimulating encounters, whether at the social events in the old towns of Rhodes and Lindos or in the hotel restaurants. Ideas about collaboration, learning, and research flowed like wine from an ancient urn.

The interdisciplinary CSCL community has always valued a diversity of theories, methods, goals, disciplines, and approaches. Whether because of the historical perspective of Greece, the intensity of the Mediterranean sun, or the growing maturity of the field, people were able to make pointed statements in favor of preferred perspectives-without denigrating the value of alternative opinions. The tension of diverse perspectives seemed to animate the community more than ever, stimulating new insights.

\footnotetext{
G. Stahl $(\bowtie)$

Drexel University, Philadelphia, PA, USA

e-mail: Gerry.Stahl@drexel.edu

F. Hesse

Knowledge Media Research Center, Tubingen, Germany

e-mail: f.hesse@iwm-kmrc.de
} 
If you missed this conference, make plans for ICLS 2010 in Chicago (June 28-July 2; paper deadline October 30) and CSCL 2011 in Hong Kong.

\section{Four years of $i j C S C L$}

The ijCSCL Board met during the conference to review the journal's progress. To date, the journal has published 75 articles by 167 authors from 21 countries. Through subscriptions to ISLS members and distribution by Springer, $i j C S C L$ is now available to more than 7,500 universities, research libraries, corporate and government institutions - that is, about 15 million users worldwide. Electronic copies of all articles can be downloaded from http:// www.springer.com/journal/11412 and free pre-print versions from http://ijCSCL.org/? go $=$ contents. The number of downloads from each of these sites has more than doubled each year that ijCSCL has existed-now more than a thousand copies of articles are downloaded each month from each site.

The continued high quality of the articles published in ijCSCL is due to the selectivity and the feedback to authors from reviewers. The following people have contributed more than 500 reviews:

Shaaron Ainsworth, Rick Alterman, Jerry Andriessen, Hans Christian Arnseth, Gerardo Ayala, Michael Baker, Maria Bannert, Liam Bannon, Sasha A. Barab, Brigid Barron, Phillip Bell, Daniel Bodemer, Jacqueline Bourdeau, Paul Brna, Bertram Bruce, Amy Bruckman, Juergen Buder, Murat Perit Cakir, John M. Carroll, Annamaria Carusi, Seth Chaiklin, Carol K.K. Chan, Tak-Wai Chan, Elizabeth Sandra Charles, Cesar Alberto Collazos, Ulrike Cress, Charles Crook, Lucilla Crosta, Harry Daniels, Ton de Jong, Sharon Derry, Pierre Dillenbourg, Angelique Dimitrakopoulou, Lone Dirckinck-Holmfeld, Paul Dourish, Alison Druin, Nathan Dwyer, Noel Enyedy, Michael A Evans, Martha D. Fewell, Frank Fischer, Brian Foley, Lachlan Forsyth, Andrea Forte, Hugo Fuks, Bill Gaver, Sean Goggins, Ricki Goldman, Jonathan Grudin, Frode Guribye, Joerg M. Haake, Kai Hakkarainen, Paivi Hakkinen, Rogers Hall, Andreas Harrer, Wu He, Thomas Herrmann, Friedrich W. Hesse, Cindy E. Hmelo-Silver, Christopher Hoadley, Ulrich Hoppe, Christine Joyce Howe, James M. Hudson, Sanna Jurvela, Patrick Jermann, Richard Joiner, Christopher Jones, Regina Jucks, Yasmin Kafai, Yael Kali, Victor Kaptelinin, Manu Kapur, Fengfeng Ke, Andrea Kienle, Joachim Kimmerle, Paul A. Kirschner, Lars Kobbe, Matthew J. Koehler, Timothy Koschmann, Ingeborg Krange, Kari Kuutti, Therese Laferrivre, Minna Helena Lakkala, Victor Lally, Mary Lamon, Johann Ari Larusson, Nancy Law, Erno Lehtinen, Lasse Lipponen, Jacques Lonchamp, Chee-Kit Looi, Rose Luckin, Sten R. Ludvigsen, Andreas Lund, Kristine Lund, Johan Lundin, Richard Medina, Naomi Miyake, Anders Morch, Joan K Moss, Daisy Mwanza-Simwami, Bonnie Nardi, Brian C. Nelson, Bernhard Nett, Matthias Nuckles, Angela O’Donnell, Hiroaki Ogata, Claire O’Malley, Jun Oshima, Roy Pea, Ruediger Pfister, Janet Read, Thomas C. Reeves, Peter Reimann, Ann Renninger, Jochen Rick, Tim Sean Roberts, Markus Rohde, Jeremy Roschelle, Carolyn P. Rose, Liam Rourke, Nikol Rummel, Nadira Saab, Roger Saljo, Johann W Sarmiento, Marelene Scardamalia, Lynette Schaverien, Tammy Schellens, Gregg Schraw, Baruch Schwarz, Anna Sfard, David Williamson Shaffer, Wesley Shumar, Amy Soller, Nancy Songer, Hans Spada, Marc Stadtler, Gerry Stahl, Danae Stanton Fraser, Constance Steinkuehler, Jan-Willem Strijbos, Masanori Sugimoto, Daniel Suthers, Berthel Sutter, Gustav Taxon, Josie Taylor, 
Ramon Prudencio Toledo, Jan van Aalst, Ravi Kiran Vatrapu, Marjaana Veermans, Barbara Wasson, Jim Waters, Rupert Boudewijn Wegerif, Armin Weinberger, Gordon Wells, James Wertsch, Martin Wessner, Tobin Frye White, Volker Wulf, Fatos Xhafa, Ling Ling Yen, Joyce Yukawa, Nan Zhou.

\section{Time is precious}

The panoply of modern science has arisen in the two millennia since the golden age of Greece; the CSCL research community has evolved in the past two decades; school learning takes place in semesters and years; while a discussion can turn in a fraction of a minute. During these various periods, the nature of the variables of interest-like competence, development, interaction - may themselves vary. Peter Reimann proposes an event-centered approach as an alternative to conventional variable-centered methodologies for analyzing the processes that unfold over extended periods of time in CSCL settings. He argues that tracking events can be more responsive to changing circumstances than plotting values of presumably fixed variables. Furthermore, event-centered analysis can account for a richer range of causality and a broader spectrum of reporting, including narratives.

His paper reflects on the nature of multiple analytic methods in CSCL at a fundamental conceptual level, citing diverse efforts representative of current approaches. Although it mentions conversation analysis, uptake diagrams, and thick descriptions, it does not clearly distinguish these as taking the participants' perspective on semantics, temporality, or interaction generally. The mundane ways in which a question can elicit an answer within a unique CSCL situation, for instance, may not be reducible to a probability measure between events, but may require an understanding of the human semantics and interactional pragmatics in order to capture the essential processes of collaborative learning. Nevertheless, the article provides a rich and important contribution to the "timely" issue of multiple analytic approaches within CSCL.

\section{Knowledge-creation discourses}

Jan van Aalst extends the considerable discourse within CSCL related to Knowledge Forum as a technological support for knowledge building or knowledge creation. He first clarifies the often-confused terminology of alternative theories of learning, and then operationalizes his distinctions within a coding scheme, applied to the work of four groups in a classroom. He clearly distinguishes "knowledge creation"-as the community improvement of ideas - from a naïve realist transmission model of "knowledge sharing" and a cognitive psychology constructionist model of "knowledge construction." His coding scheme is able to distinguish the differential ability of the student groups to engage in knowledge creation through their work in Knowledge Forum. A look at the decisive codes is suggestive of pedagogical issues to consider in promoting knowledge creation.

Despite its extensive clarification, this article - like so much of the related literaturespeaks ambiguously about the "sense of community," which it highlights as key to knowledge construction. Both the acquisition and the construction models focus on the individual student as the unit of description; knowledge construction differs decisively on this point. With its orientation to the progressive public refinement of ideas, theories, and other knowledge artifacts, knowledge creation is a social activity. But the paper's case- 
study analysis is exclusively at the small-group level. Between-group differences are discussed in terms of social practices, sense of community, and innovation ecology although all the groups were in the same classroom, school, and world. In distinguishing knowledge creation from theories of individual learning, the paper fails to distinguish small-group from community processes. In fact, it shows how the theory of knowledge creation-derived from the practices of large scientific communities - can be applied to collaborative learning in small groups of students.

\section{Collaborative learning in dual-interaction spaces}

The contrast of fundamentally different approaches to analyzing interactions in CSCL settings pervaded the CSCL 2009 conference, from the workshop on multivocality the first day to the closing panel on 20 years of CSCL. In this issue, both Reimann's and von Aalst's articles explicitly contrast approaches based on incommensurable theories. Jacques Lonchamp takes the opposite tack, proposing a systematic integration of three analytic approaches. He describes three levels of analysis - dialog, knowledge, and action - which he claims fit together like semantics, syntax, and pragmatics to provide an integrated view of communication. Adding to the complexity, he considers dual-interaction environments built using his generic and customizable Omega+ model (Lonchamp 2006). One can usefully compare his analysis of a case study of students constructing UML use-case diagrams with the detailed analysis by Çakır et al. (2009) of students drawing and chatting about geometric patterns in another synchronous dual-interaction system. Such a comparison illustrates the difference between a designer perspective and a practice perspective.

\section{Studying digital resources}

In a complicated software tool like Microsoft Word, spell checking seems like a simple, well-defined, and fully understood function. Asta Cekaite's detailed analysis of several students using a spell checker shows, however, how this function can be enacted in surprisingly rich and creative ways in the situated practices of real users. As recently discussed by Dohn (2009), the "affordances" of an artifact are not fully predefined by the technology. Here we see that a spell checker can be used to support student writing through a variety of methods closely tied to the activity or interaction of the students. While both the spell-checking technology and the discourse of the students may seem trivial, the implication of this paper is that this kind of detailed case study can reveal the concrete affordances of designed technologies that go far beyond the intentions, affordances, and assumptions of the designers.

\section{The tensions of educational web 2.0}

In the new article by Nina Bonderup Dohn, we return to the theoretical tension between knowledge sharing (as an acquisitionist or transmission model of learning) and knowledge construction (as a participationist or social model). Building on her recently published analysis of affordances (Dohn 2009), the author clearly lays out the challenges posed by trying to adopt Web 2.0 technologies (wikis, blogs, Wikipedia, Facebook, Flickr, YouTube, 
Second Life, etc.) for educational purposes in university courses. The affordances of these technologies depend on our established practices as consolidated in our body schemas (Merleau-Ponty) or habitus (Bourdieu). The conventional focus on educational outcomes of individual learners, systems of grading, traditions of instruction, and expectations of student development all militate against the Web 2.0 goal of collective wisdom and social networking. Once again, in the challenges of using recent forms of computer support we see the fundamental tension in collaborative learning: how to align and integrate learning at the individual, small-group, and community levels.

\section{References}

Çakır, M. P., Zemel, A., \& Stahl, G. (2009). The joint organization of interaction within a multimodal CSCL medium. International Journal of Computer-Supported Collaborative Learning, 4(2), 115-149. Available at http://dx.doi.org/10.1007/s11412-009-9061-0.

Dohn, N. B. (2009). Affordances revisited: articulating a Merleau-Pontian view. International Journal of Computer-Supported Collaborative Learning, 4(2), 151-170. Available at http://dx.doi.org/10.1007/ s11412-009-9062-z.

Lonchamp, J. (2006). Supporting synchronous collaborative learning: a generic, multi-dimensional model. International Journal of Computer-Supported Collaborative Learning, 1(2), 247-276. Available at http://dx.doi.org/10.1007/s11412-006-8996-7. 